\title{
Effect of slow, deep breathing on visceral pain perception and its underlying psychophysiological mechanisms
}

Citation for published version (APA):

Gholamrezaei, A., Van Diest, I., Aziz, Q., Pauwels, A., Tack, J., Vlaeyen, J. W. S., \& Van Oudenhove, L. (2022). Effect of slow, deep breathing on visceral pain perception and its underlying psychophysiological mechanisms. Neurogastroenterology and Motility, 34(4), 13. [e14242]. https://doi.org/10.1111/nmo.14242

Document status and date:

Published: 01/04/2022

DOI:

10.1111/nmo.14242

Document Version:

Publisher's PDF, also known as Version of record

\section{Document license:}

Taverne

Please check the document version of this publication:

- A submitted manuscript is the version of the article upon submission and before peer-review. There can be important differences between the submitted version and the official published version of record.

People interested in the research are advised to contact the author for the final version of the publication, or visit the DOI to the publisher's website.

- The final author version and the galley proof are versions of the publication after peer review.

- The final published version features the final layout of the paper including the volume, issue and page numbers.

Link to publication

\footnotetext{
General rights rights.

- You may freely distribute the URL identifying the publication in the public portal. please follow below link for the End User Agreement:

www.umlib.nl/taverne-license

Take down policy

If you believe that this document breaches copyright please contact us at:

repository@maastrichtuniversity.nl

providing details and we will investigate your claim.
}

Copyright and moral rights for the publications made accessible in the public portal are retained by the authors and/or other copyright owners and it is a condition of accessing publications that users recognise and abide by the legal requirements associated with these

- Users may download and print one copy of any publication from the public portal for the purpose of private study or research.

- You may not further distribute the material or use it for any profit-making activity or commercial gain

If the publication is distributed under the terms of Article $25 \mathrm{fa}$ of the Dutch Copyright Act, indicated by the "Taverne" license above, 


\title{
Effect of slow, deep breathing on visceral pain perception and its underlying psychophysiological mechanisms
}

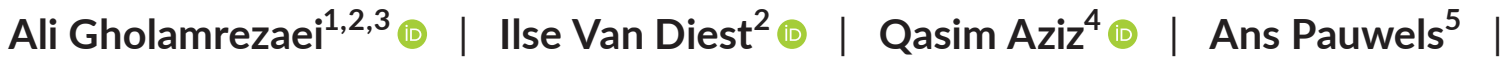

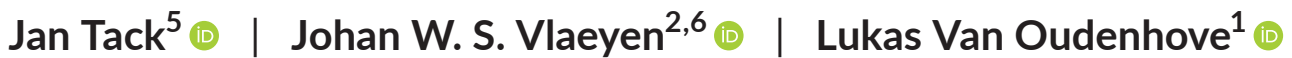

${ }^{1}$ Laboratory for Brain-Gut Axis Studies (LaBGAS), Translational Research Center for Gastrointestinal Disorders (TARGID), Department of Chronic Diseases,

Metabolism and Ageing, KU Leuven, Leuven, Belgium

${ }^{2}$ Health Psychology Research Group, KU Leuven, Leuven, Belgium

${ }^{3}$ Pain Management Research Institute, Faculty of Medicine and Health, The University of Sydney, Sydney, NSW, Australia

${ }^{4}$ Centre for Neuroscience and Trauma, Blizard Institute, Wingate Institute of Neurogastroeneterology, Queen Mary University of London, London, UK

${ }^{5}$ Gastrointestinal Sensitivity and Motility Research Group, Translational Research Center for Gastrointestinal Disorders (TARGID), Department of Chronic Diseases, Metabolism and Ageing, KU Leuven, Leuven, Belgium

${ }^{6}$ Experimental Health Psychology, Maastricht University, Maastricht, The Netherlands

\section{Correspondence}

Ali Gholamrezaei, Pain Management Research Institute, Level 2 Douglas Building, Royal North Shore Hospital, St Leonards, NSW 2065, Australia.

Email: ali.gholamrezaei@sydney.edu.au

Funding information

Vlaamse regering, Grant/Award Number: METH/14/05 and METH/15/011;

KU Leuven, Grant/Award Number: DBOF/14/02

\begin{abstract}
Background: Studies using somatic pain models have shown the hypoalgesic effects of slow, deep breathing. We evaluated the effect of slow, deep breathing on visceral pain and explored putative mediating mechanisms including autonomic and emotional responses.

Methods: Fifty-seven healthy volunteers (36 females, mean age $=22.0$ years) performed controlled, deep breathing at a slow frequency (6 breaths per minute), controlled breathing at a normal frequency (14 breaths per minute; active control), and uncontrolled breathing (no-treatment control) in randomized order. Moderate painful stimuli were given during each condition by delivering electrical stimulation in the distal esophagus. Participants rated pain intensity after each stimulation. Heart rate variability and self-reported arousal were measured during each condition.
\end{abstract}

Key Results: Compared to uncontrolled breathing, pain intensity was lower during slow, deep breathing (Cohen's $d=0.40$ ) and normal controlled breathing $(d=0.47$ ), but not different between slow, deep breathing and normal controlled breathing. Arousal was lower $(d=0.53,0.55)$ and heart rate variability was higher $(d=0.70,0.86)$ during slow, deep breathing compared to the two control conditions. The effect of slow, deep breathing on pain was not mediated by alterations in heart rate variability or arousal but was moderated by pain catastrophizing.

Conclusions and Inferences: Slow, deep breathing can reduce visceral pain intensity. However, the effect is not specific to the slow breathing frequency and is not mediated by autonomic or emotional responses, suggesting other underlying mechanisms (notably distraction). Whether a long-term practice of slow, deep breathing can influence (clinical) visceral pain warrants to be investigated.

KEYWORDS

autonomic nervous system, baroreflex, breathing exercises, pain, vagus nerve

\section{1 | INTRODUCTION}

Slow, deep breathing is a self-management intervention and a common component of several non-pharmacological treatments such as relaxation, hypnotherapy, and yoga, which are commonly being used for pain management. ${ }^{1}$ Several experimental studies using somatic pain models have shown the hypoalgesic effects of slow, deep breathing. The proposed underlying mechanisms include cognitive 
(eg, distraction), emotional (eg, reduced arousal), and autonomic (eg, increased parasympathetic activity) modulations. ${ }^{2}$

Slow, deep breathing can increase vagal afferent signaling at different levels. Deep breathing increases stimulation of the pulmonary stretch receptors and afferent signaling, which mainly run in the vagus nerve and give inputs to the nucleus of the solitary tract in the brain stem. They also synapse with ascending circuits terminating at subcortical and cortical levels (eg, insular cortex and amygdala) and contribute to sensory, emotional, and cognitive processing of the respiratory signals. ${ }^{3}$ Slow, deep breathing can also increase vagal afferent signaling via phasic stimulation of the arterial baroreceptors by augmenting fluctuations of blood pressure at slow frequency. ${ }^{4,5}$ Baroreceptors are mechanoreceptors mainly located in the aortic arch and carotid sinus. The baroreflex is responsible for rapid control of arterial blood pressure; an increase in blood pressure increases baroreceptors afferent signaling which is transmitted via the carotid sinus and aortic depressor nerves (branches of the glossopharyngeal and the vagus nerves, respectively) to the nucleus of the solitary tract. This ultimately leads to sympathoinhibition and increased cardiac vagal output, which result in a decrease in heart rate and blood pressure. ${ }^{6}$ The nucleus of the solitary tract has direct and indirect projections to several brain areas involved in pain regulation (eg, periaqueductal gray and locus coeruleus). ${ }^{7}$ Several animal and human studies using different methods of baroreceptors and vagus nerve stimulation have found hypoalgesic or antinociceptive effects. ${ }^{8-15}$

Despite its use as a pain self-management intervention and some promising findings from clinical and experimental studies, evidence for the effect of slow, deep breathing on pain remains equivocal and the underlying mechanisms are poorly understood. ${ }^{2}$ Previous experiments have mostly used somatic pain models, and the effect of slow, deep breathing on visceral pain is less investigated. There are differences between somatic and visceral pain at both the neural and behavioral levels. ${ }^{16}$ Visceral pain has a stronger affective dimension. ${ }^{17,18}$ Considering emotional modulation as one of the proposed mechanisms for the hypoalgesic effects of slow, deep breathing ${ }^{2}$ and also according to some reports that heightened arousal may attenuate baroreceptor modulation of nociception, ${ }^{19,20}$ the results of previous studies on the influence of slow, deep breathing on somatic pain cannot necessarily be generalized to visceral pain. The only experimental study in this regard by Botha et al. ${ }^{21}$ demonstrated that slow, deep breathing during distal esophageal acid infusion inhibits the development of secondary hyperalgesia at the level of the proximal esophagus, probably by increasing parasympathetic activity.

We evaluated the effect of slow, deep breathing on visceral pain and investigated some putative mediating mechanisms including autonomic and emotional responses. We investigated whether the hypoalgesic effect of slow, deep breathing is specific to the slow breathing frequency and related psychophysiological responses. To achieve these aims, in addition to a no-treatment control condition (uncontrolled breathing), we used an active control condition (controlled breathing at a normal frequency) similar (as possible) to slow, deep breathing. This enabled us to control for the potential effects of distraction and expectation. ${ }^{22}$ We hypothesized that slow, deep

\section{Key points}

- Paced breathing, at slow or normal frequencies, can reduce visceral pain intensity.

- Slow breathing increases heart rate variability and reduces anticipatory arousal.

- Effect of slow breathing on visceral pain is not mediated by autonomic or emotional responses but is moderated by pain catastrophizing.

- Applications of paced breathing in clinical conditions of visceral pain and effects of long-term practice warrants to be investigated.

breathing reduces pain intensity by autonomic and/or emotional modulations. Accordingly, we predicted that 1) pain intensity would be lower during slow, deep breathing and normal controlled breathing compared to uncontrolled breathing, 2) pain intensity would be lower during slow, deep breathing compared to normal controlled breathing, and 3) the effect of slow, deep breathing on pain would be mediated by increased parasympathetic activity and/or decreased arousal.

\section{2 | MATERIALS AND METHODS}

\section{1 | Participants and setting}

This within-subject experimental study was conducted in the Laboratory for Brain-Gut Axis Studies (KU Leuven, Belgium). Healthy volunteers including males and females aged 18-45 years were invited. Exclusion criteria included self-report of any of the following conditions: cardiovascular, respiratory, or neurological diseases, acute or chronic pain, psychiatric disorders, regular medication use other than contraceptives, pregnancy, current smoking or any other nicotine consumption, and practicing breathing exercises on a regular basis. Also, those with a body mass index of $<18.5$ or $>30 \mathrm{~kg} / \mathrm{m}^{2}$ and those with a score of $\geq 10$ in any subscale of the Patient Health Questionnaires (PHQ; anxiety, somatic, and depressive symptoms) ${ }^{23}$ were not included in the study. Participants were asked to refrain from strenuous exercise and caffeine and alcohol intake for at least $12 \mathrm{~h}$, and fast (for solid food) for $4 \mathrm{~h}$ prior to testing. The study was approved by the Ethics Committee Research UZ/KU Leuven (\#S60370), and informed consent was obtained from all participants.

\subsection{Instruments and measurements}

\subsection{1 | Physiological measures}

Respiratory movements were recorded using an aneroid chest bellows, secured around the upper abdomen. Cardiac electrical activity 
was recorded using electrocardiography (ECG) electrodes placed at the lead II configuration. Continuous noninvasive arterial pressure was recorded at the finger using the volume clamp method. ${ }^{24}$ Arm blood pressure was measured using an automatic digital sphygmomanometer. Skin conductance was measured with the electrodes being placed to the hypothenar palm of the left hand. All of these physiological signals were recorded and digitized at $1 \mathrm{kHz}$ sampling rate using AFFECT software version 4.0 (KU Leuven). ${ }^{25}$ See supporting information for details of the devices used.

\subsection{2 | Self-reported measures}

Pain intensity was assessed using an 11-point numerical rating scale (NRS) ranging from 0 (not painful at all) to 10 (most intense pain imaginable). Pain unpleasantness was assessed by an 11-point NRS ranging from 0 (not unpleasant at all) to 10 (the most unpleasant pain imaginable). Participants were instructed to distinguish between pain intensity and unpleasantness. ${ }^{26}$ Participants were also asked to indicate (draw) the area where they perceived the pain on a paper with a schematic picture of the body; the referred pain area can be considered a proxy for central pain processing. ${ }^{27}$ Emotional arousal was assessed using the 9-point Self-Assessment Manikin (SAM) scale with scores ranging from 1 (extremely calm/relaxed) to 9 (extremely aroused/agitated). ${ }^{28}$

In addition to the above, we also measured pain catastrophizing, using the Pain Catastrophizing Scale with 13 items and a total score of $0-52,{ }^{29}$ and fear of pain, using the short version of the Fear of Pain Questionnaire with nine items and a total score of $9-45{ }^{30}$
These questionnaires were completed before the test day and participants were asked to respond based on their prior pain experience and/or expectations.

\section{3 | Procedures}

The procedure of the experiment is outlined in Figure 1. Before the test, participants completed an online survey including demographic data and the questionnaires. They received an information sheet explaining the study's aim and procedures. The study's aim was mentioned as "to evaluate the effect of different breathing exercises on pain in the esophagus." No further information was provided about breathing exercises or their effects.

\subsection{1 | Esophageal intubation}

A flexible catheter (2 $\mathrm{mm}$ in diameter) with 2 ring electrodes attached to its end was used (UniTip Katheter, REF K6016-EL30964-D, UNISENSOR). The catheter was placed trans-nasally, and the electrodes were positioned at the distal (visceral) esophagus. ${ }^{31}$ The distance between the nares and the lower esophageal sphincter was estimated based on a formula ( $9.31+$ height in $\mathrm{cm} \times 0.197)$ with a small estimation error. ${ }^{32}$ The catheter electrodes were positioned $5 \mathrm{~cm}$ above the lower esophageal sphincter. ${ }^{31}$ The interelectrode impedance was measured using an impedance monitor (EL-CHECK, Biopac Systems, Inc.) at different stages to ensure sufficient mucosal contact $(<10 \mathrm{k} \Omega){ }^{33}$ See supporting information for further details.

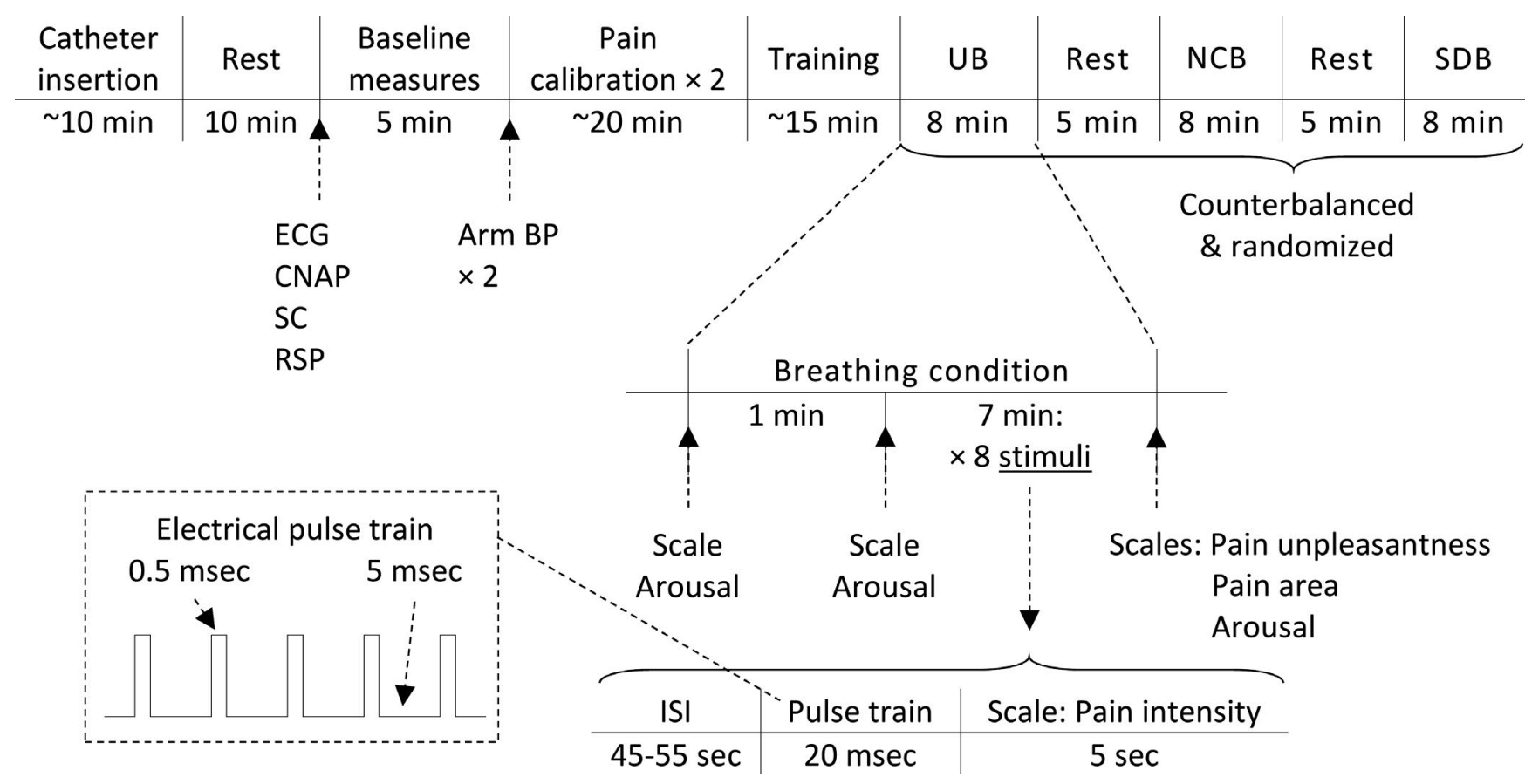

FIGURE 1 The study procedure. Abbreviations: BP, blood pressure; CNAP, continuous noninvasive arterial pressure; ECG, electrocardiography; ISI, inter-stimulus interval; NCB, normal controlled breathing; RSP, respiratory measure; SC, skin conductance; SDB, slow, deep breathing; UB, uncontrolled breathing 


\subsection{2 | Baseline measures}

The participant was seated in a comfortable chair with the upper body and arms being supported. Since esophageal intubation can provoke autonomic responses, participants were allowed to rest for $15 \mathrm{~min}$ after attaching the equipment and electrodes to have enough recovery time. ${ }^{34}$ The last $5 \mathrm{~min}$ were considered as the baseline physiological state.

\subsection{3 | Stimulus calibration}

We used electrical stimulation to induce pain as it is a common method in experimental studies of visceral pain. ${ }^{35}$ The threshold for moderate pain intensity (score of 5 on the 11-point NRS) was determined using the adaptive staircase method (see Figure S1 in supporting information). ${ }^{36} \mathrm{~A}$ train of 5 square-wave electrical pulses (500 $\mu$ s pulse width) was delivered at a frequency of $200 \mathrm{~Hz}$ using a standard electrical stimulator (DS7, Digitimer Ltd). The stimulus calibration procedure was repeated two times, and the threshold values were averaged. The ECG was monitored during stimulus calibration. The stimulation was stopped at a maximum allowed current of $60 \mathrm{~mA}$ for safety. ${ }^{37}$

\subsection{4 | Training for controlled breathing}

A visual cue (vertical bar) was presented on a computer screen (AFFECT software version 4.0) to guide participants while breathing at the specified breathing frequencies. Participants practiced controlled breathing at two frequencies of $0.23 \mathrm{~Hz}$ (14 breaths per minute) and $0.1 \mathrm{~Hz}$ (6 breaths per minute), 1 min each, and under the supervision of the experimenter. After receiving feedback, they practiced each of the controlled breathing conditions for $2 \mathrm{~min}$. The inspiration to expiration ratio was 1:2. ${ }^{38}$ Controlled breathing at $0.23 \mathrm{~Hz}$ was used as an active control condition considering the average breathing rate of $\sim 14$ breaths per minute at rest in our previous studies. ${ }^{38}$ Tidal volume was not controlled; however, participants were asked to not perform deep breathing at $0.23 \mathrm{~Hz}$, and to perform deep but "comfortable" breathing during slow, deep breathing (see supporting information for further details).

\subsection{5 | Main test}

The main test included three within-subject breathing conditions of 8 min each: uncontrolled breathing (no-treatment control), controlled breathing at a normal frequency $(0.23 \mathrm{~Hz}$, active control), and controlled, deep breathing at a slow frequency $(0.1 \mathrm{~Hz}$, ie, slow, deep breathing), Figure 1. For the uncontrolled breathing condition, participants were asked to not change their breathing rate or depth and to perform their "normal breathing."

Right before starting each condition, participants rated their arousal level (baseline arousal) and then performed the assigned type of breathing. One minute after starting the breathing condition, participants rated their arousal level again (pre-stimulation arousal) and then continued the breathing condition for 7 min during which eight painful stimuli were given. The inter-stimulus intervals were randomized between 45 and $55 \mathrm{~s}$. Participants rated the intensity of pain immediately after each stimulation. After each breathing condition, participants rated pain unpleasantness and arousal level (arousal during stimulation) and indicated pain area according to what they had experienced overall during the breathing condition. There was a 5 -min rest period between the breathing conditions. The order of the breathing conditions was counterbalanced and randomized between participants (see the supporting information for further details). Testing was done in a single 2-h session, between 9 am and $5 \mathrm{pm}$, in a sound-attenuated and temperature-controlled $\left(22-25^{\circ} \mathrm{C}\right)$ room.

\subsection{Data reduction and analysis}

All physiological signals were processed using custom-written algorithms in MATLAB software (R2018b, Mathworks, Inc.) which we have used in other studies and with the details provided in the supporting information. ${ }^{4,5}$ Briefly, the average respiratory rate (breath per minute) and respiratory amplitude were extracted from the respiratory signal. R-wave peaks were determined in the ECG signal, and the RR-intervals were calculated. Mean RR-interval, representing tonic autonomic activity, and root mean square of the successive differences (RMSSD) in RR-intervals, representing vagally-mediated HRV (vmHRV), were calculated. ${ }^{39}$ We selected these time-domain $H R V$ indexes because of the large differential effects of breathing frequency on frequency-domain measures of HRV. ${ }^{4}$ According to our previous studies, increased vmHRV during slow, deep breathing is mainly mediated by the increased blood pressure fluctuations over the respiratory cycles, which suggests increased stimulation of the arterial baroreceptors and cardiac vagal afferent signaling. ${ }^{4,5}$ Beatto-beat systolic and diastolic blood pressure values were extracted from the arterial blood pressure signal. Cardiovagal baroreflex sensitivity was calculated using the sequence method. ${ }^{40}$ The amplitude of pain-evoked skin conductance response (SCR) was measured according to the available guidelines. ${ }^{41}$ The extent of the referred pain area was measured after digitizing the drawings and counting the pixel numbers in the pain area using the MATLAB software.

\section{5 | Statistical analyses}

\subsection{1 | Sample size}

The required sample size to detect an effect size $(f)$ of $0.25^{22}$ using repeated measure ANOVAs with a power of 0.9 and alpha (type I error) of 0.05 was calculated as 58 using the G*Power software. ${ }^{42}$ Considering possible drop-outs, and to have counterbalanced sequences for the three breathing conditions, we included 66 participants in the study. 
FIGURE 2 Pain intensity over 8 stimuli (A) and averaged over stimuli (per subject/condition, B) between breathing conditions. Data are estimates (leastsquares means and error bars are $\pm 2 \mathrm{SE}$ ). Abbreviations: NCB, normal controlled breathing; SDB, slow, deep breathing; UB, uncontrolled breathing

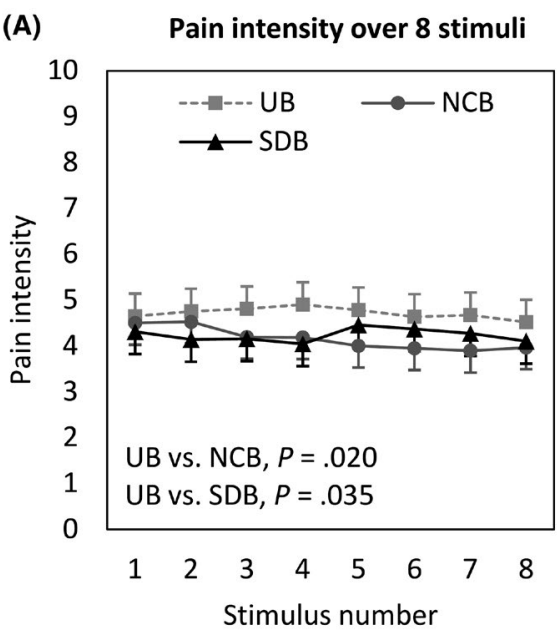

(B) Pain intensity averaged over 8 stimuli

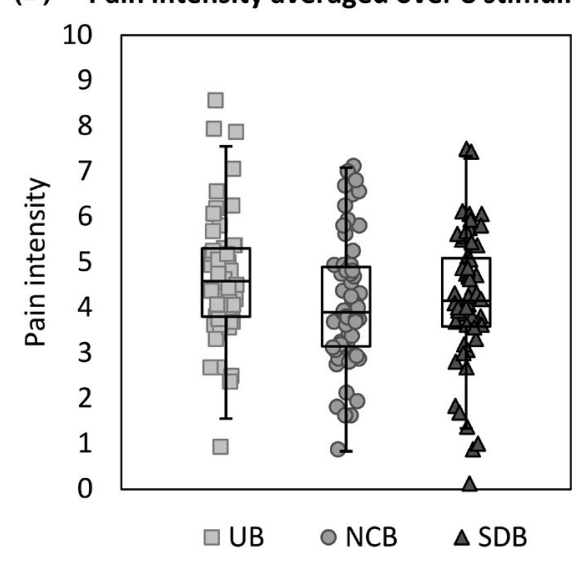

\subsection{2 | Statistical methods}

The study's primary outcome was pain intensity. Secondary outcomes included pain unpleasantness, size of the referred pain area, and amplitude of pain-evoked SCR. Hypothesized mediators were autonomic (ie, vmHRV) and emotional (ie, arousal) responses. Marginal mixed models (PROC MIXED) were performed with the breathing condition as the main within-subject factor. Pain intensity was not averaged across the 8 stimuli in each breathing condition and therefore breathing condition was included in the model as the repeated factor along with the stimulation number using covariance structure of (unstructured @ autoregressive). For other variables where there was only one measure per breathing condition (eg, pain unpleasantness), we used the unstructured covariance structure. Log transformation was used to approximate the residuals to normality if needed. Pairwise contrasts were performed, and the Holm-Bonferroni (stepdown) method was applied for correcting $p$ values for multiple comparisons. ${ }^{43}$ For the effect size, Cohen's $d$ was calculated based on the results of contrasts. ${ }^{44}$ Data are presented as estimates [leastsquares means, standard error (SE), and 95\% confidence interval]. Demographic and baseline psychometric physiological characteristics (see 2.3.2. Baseline measures and Figure 1) were subsequently included in the main model to explore possible factors associated with pain intensity (main effect of the covariates) and possible moderators of response to the intervention (interaction between the covariate and breathing condition). For this purpose, we used the standardized variables ( mean $=0$ and standard deviation $=1$ ).

\subsection{3 | Mediation analyses}

Multilevel mediation analysis was performed to test whether the influence of the breathing condition on pain intensity ratings of each stimulus is mediated via alterations in vmHRV prior to the stimulus. Data corresponding to all stimuli were included in this analysis. Since the inter-stimulus intervals were between 45 and $55 \mathrm{~s}$, we used a pre-stimulus 30-second window to extract vmHRV (ie, RMSSD) as the possible mediator for each pain intensity rating. Studies have shown that RMSSD can be reliably measured from ultra-short records of $10 \mathrm{~s}$ to $1 \mathrm{~min} .{ }^{45}$ Single-level mediation analysis was applied to test whether the influence of the breathing condition on pain intensity is mediated via alterations in arousal level (ie, from baseline to pre-stimulation, see Figure 1).

Statistical significance was set at $p<.05$. Statistical analyses were performed using the SAS ${ }^{\circledR}$ Studio version 3.8 (SAS Institute Inc.). Multilevel mediation analysis with bootstrapping was performed using the CANlab mediation toolbox in the MATLAB software. ${ }^{46}$

\section{3 | RESULTS}

\section{1 | Participants}

Out of 90 volunteers, 66 were eligible and entered the study. Nine participants were excluded during the study due to technical issues $(n=6)$ or adverse events $(n=3)$. Finally, 57 participants completed the study, including 36 females and 21 males with a mean age of 22.0 years (standard deviation 3.8, range 18-39, see supporting information for further details).

\section{2 | Manipulation check}

Participants were able to perform controlled breathing as instructed and at the specified frequency without the interference of the pain stimuli (see Table S2 and Figure S2 in the supporting information).

\section{3 | Pain intensity and unpleasantness, referred pain area, and evoked SCR}

Pain intensity ratings over 8 stimuli in each breathing condition and averaged values are presented in Figure 2A,B, respectively. The effect of breathing condition on pain intensity was significant ( $F=4.6, p=.011)$. Compared to uncontrolled breathing, pain intensity was lower during slow, deep breathing (DLSM [SE] $=0.4$ [0.1], 
$t(1,110)=2.41, p=.035, d=0.40)$ and normal controlled breathing $(\mathrm{DLSM}[\mathrm{SE}]=0.5[0.1], t(1,110)=2.75, p=.020, d=0.47)$. However, there was no significant difference between slow, deep breathing and normal controlled breathing in pain intensity $(p=.718, d=0.06)$.

The effects of breathing condition on pain unpleasantness $(F(2,56)=2.50, p=.091$, Table S3 $)$ and the size of referred pain area $(F(2,56)=2.20, p=.120$, Table S3, Figure S3) were not significant. The size of the pain area was, however, associated with pain intensity (averaged over 8 stimuli, estimate $[\mathrm{SE}]=0.7[0.3]$, $F(1,56)=6.1, p=.016)$ and pain unpleasantness (estimate $[\mathrm{SE}]=1.2$ [0.2], $F(1,56)=38.0, p<.001)$. There was no significant effect of breathing condition on the amplitude of the pain-evoked SCR; $F(2,100)=0.06, p=.944$ (Table S3, Figure S4A,B). Pain-evoked SCR was, however, associated with pain intensity (estimate $[\mathrm{SE}]=0.2$ [0.1], $F(1,1085)=243.7, p<.001)$.

\subsection{Heart rate variability}

Effects of breathing condition on RR-interval $(F(2,55)=17.2, p<.001)$ and $\operatorname{RMSSD}(F(2,55)=51.8, p<.001)$ were significant (Table 1$)$. Compared to uncontrolled breathing, RR-interval was lower during slow, deep breathing (DLSM [SE] = $20[4] \mathrm{ms}, t(1,55)=4.25, p<.001$, $d=0.17$ ) and normal controlled breathing (DLSM [SE] $=30$ [5] ms, $t(1,55)=5.68, p<.001, d=0.24)$. RMSSD was higher during slow, deep breathing compared to uncontrolled breathing (DLSM [SE] $=26$ [2] ms, $t(1,55)=9.95, p<.001, d=0.86)$ and normal controlled breathing (DLSM $[\mathrm{SE}]=23[2] \mathrm{ms}, t(1,55)=8.48, p<.001, d=0.70)$.

\section{5 | Blood pressure}

The effects of breathing condition on average systolic $(F(2,53)=7.2$, $p=.001)$ and diastolic blood pressures $(F(2,53)=8.5, p<.001)$ were significant (Table 1). Systolic blood pressure was lower during slow, deep breathing compared to uncontrolled breathing (DLSM $[S E]=6[1] \mathrm{mmHg}$, $t(1,53)=3.8, p=.001, d=0.34)$. Diastolic blood pressure was lower during slow, deep breathing compared to uncontrolled breathing (DLSM $[\mathrm{SE}]=4[1] \mathrm{mmHg}, t(1,53)=3.8, p=.001, d=0.34)$ and normal controlled breathing (DLSM $[\mathrm{SE}]=3[1] \mathrm{mmHg}, t(1,53)=2.7, p=.015, d=0.27$ ).

\section{6 | Baroreflex sensitivity}

Effect of breathing condition on baroreflex sensitivity was significant $(F(2,53)=29.9, p<.001)$. Baroreflex sensitivity was higher during slow, deep breathing compared to uncontrolled breathing (DLSM $[\mathrm{SE}]=6[0.9] \mathrm{ms} / \mathrm{mmHg}, \mathrm{t}(1,53)=6.92, p<.001, d=0.73)$ and normal controlled breathing (DLSM $[S E]=8[1.0] \mathrm{ms} / \mathrm{mmHg}, t(1,53)=7.72$, $p<.001, d=0.95$ ). Further, it was slightly lower during normal controlled breathing compared to uncontrolled breathing (DLSM [SE] = 1 [0.4] ms/mmHg, $t(1,53)=4.50, p<.001, d=0.29$, Table 1).

\section{7 | Emotional arousal}

Effects of breathing condition on pre-stimulation arousal $(F(2,56)=6.62, p=.002)$ and arousal during stimulation $(F(2,56)=5.61$, $p=.006)$ were significant. Pre-stimulation arousal was lower during slow, deep breathing compared to uncontrolled breathing (DLSM $[\mathrm{SE}]=0.3[0.1], t(1,56)=3.07, p=.006, d=0.55)$ and normal controlled breathing (DLSM $[\mathrm{SE}]=0.4[0.1], t(1,56)=3.20, p=.006$, $d=0.53$ ). Arousal during stimulation was lower during slow, deep breathing compared to uncontrolled breathing (DLSM [SE] = 0.7 [0.2], $t(1,56)=3.33, p=.004, d=0.58$, Figure 3 , also see Table S4).

\section{8 | Possible mechanisms of action}

The effect of slow, deep breathing on pain was not mediated by alterations in the hypothesized mediators; RMSSD or arousal (Figure 4). Other factors with differences between the breathing conditions

TABLE 1 Physiological responses ${ }^{a}$ between the breathing conditions

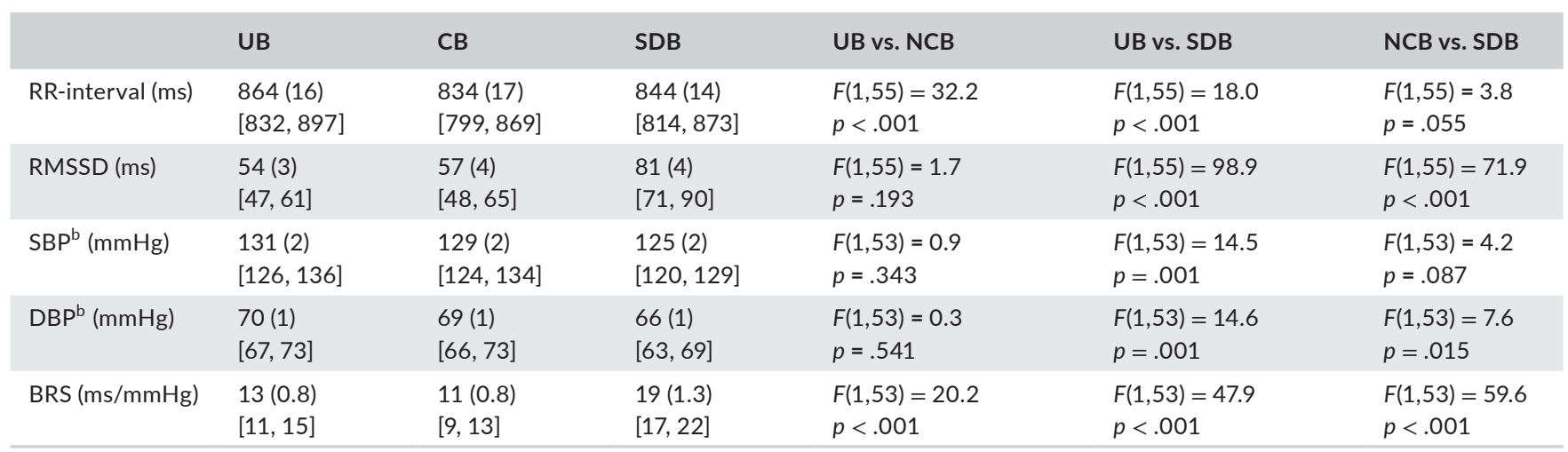

Note: Data are estimates; least-square means (standard error) and [95\% confidence interval].

Abbreviations: BRS, baroreflex sensitivity; DBP, diastolic blood pressure; NCB, normal controlled breathing; RMSSD, root mean square of successive difference; SBP, systolic blood pressure; SDB, slow, deep breathing; UB, uncontrolled breathing.

${ }^{\text {a}}$ All data are averages during each breathing condition.

${ }^{\mathrm{b}}$ From continuous arterial pressure measured at the finger. 


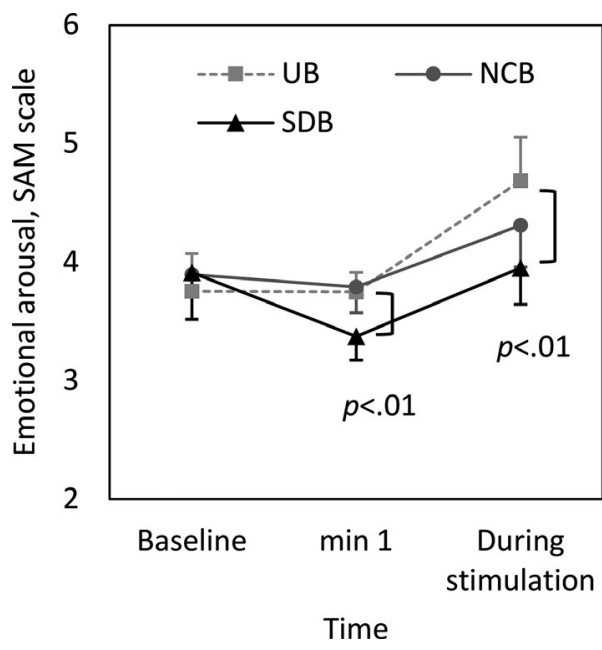

FIGURE 3 Emotional arousal at baseline, pre-stimulation (min 1), and during stimulation between the breathing conditions. Data are least-squares means, and error bars are $\pm 2 \mathrm{SE}$. Abbreviations: NCB, normal controlled breathing; SAM 9-point Self-Assessment Manikin scale with scores ranging from 1 (extremely calm/relaxed) to 9 (extremely aroused/agitated); SDB, slow, deep breathing; UB, uncontrolled breathing

were also tested as possible mediators (eg, respiratory amplitude, RR-interval), but none of these factors could explain the effect of the breathing condition on pain intensity (see Figures S5 and S6).

\subsection{Factors associated with pain intensity and moderators of response to intervention}

There was a significant interaction between pain catastrophizing and breathing condition $(F(2,1278)=3.6, p=.027)$; differences of slow, deep breathing and normal controlled breathing with uncontrolled breathing increased as a function of pain catastrophizing (Table 2, Figure 5, also see Figure S7). Among the baseline physiological parameters, higher RR-interval $(F(1,54)=6.58, \beta=-0.213$, $p=.013)$, higher RMSSD $(F(1,54)=25.24, \beta=-0.582, p<.001)$, and higher baroreflex sensitivity $(F(1,51)=18.40, \beta=-0.586, p<.001)$ were associated with lower pain intensity (Table 2).

\section{4 | DISCUSSION}

This is the first reported experiment on the influence of breathing exercises on visceral pain intensity. Our hypothesis was that slow, deep breathing reduces pain intensity by autonomic and/or emotional modulations. We found that both slow, deep breathing and normal controlled breathing reduce visceral pain intensity compared to uncontrolled breathing, though the effects were not large (Cohen's $d=0.40$ to 0.47 ). We expected that slow, deep breathing further reduces pain intensity (compared to normal controlled breathing), but this was not achieved. Moreover, the effect of slow, deep breathing on pain was not mediated by increased vagal modulation and/or reduced emotional arousal. Therefore, the findings of this study do not support our hypothesis. These findings suggest that the hypoalgesic effect of slow, deep breathing is not specific to the breathing frequency and may be due to mechanisms other than autonomic and emotional responses, notably expectancy and attentional modulation.

\section{1 | Putative mechanisms for hypoalgesic effects of slow, deep breathing}

\subsubsection{Stimulation of the arterial baroreceptors and vagal afferents}

Stimulation of the arterial baroreceptors and vagal afferents have hypoalgesic effects. ${ }^{8-15}$ Increased HRV during slow, deep breathing is mainly due to increased blood pressure fluctuations, suggesting increased stimulation of the arterial baroreceptors, and partially because of the increased tidal volume, suggesting increased pulmonary vagal afferent signaling. ${ }^{4}$ However, our findings do not support cardiac or pulmonary vagal afferent stimulation as underlying mechanisms for the effect of slow, deep breathing on visceral pain. This is similar to some other studies on somatic pain, which found no association between pain reduction and autonomic response by slow, deep breathing. ${ }^{47,48}$ In the study by Botha et al., slow, deep breathing was associated with increased vagal activity. However, whether changes in pain threshold were associated with changes in vagal activity was not reported. ${ }^{21}$ Botha et al. ${ }^{21}$ also reported that acidinduced hyperalgesia was only partially prevented during slow, deep breathing when atropine (an anticholinergic agent which may inhibit vagal effects) was injected. However, since no control (breathing) condition was used, it is not clear whether the antagonizing effect of atropine was specific to the slow breathing frequency. Atropine is an antagonist of the muscarinic acetylcholine receptors located in end organs (eg, the heart) and the brain. ${ }^{49}$ Therefore, it remains to be investigated at what level(s) atropine can counteract the hypoalgesic effects of slow, deep breathing and whether such an effect is specific to controlled and deep breathing at a slow frequency.

\subsection{2 | Emotional modulation}

Slow, deep breathing has been shown to reduce physiological arousal (sympathetic activation, parasympathetic withdrawal) and anxiety in a threat situation such as pain anticipation. ${ }^{50,51}$ In our study, slow, deep breathing reduced arousal before the stimuli were given. However, this effect did not mediate pain reduction. Busch et al. ${ }^{52}$ showed that "relaxing" is more effective than "attentive" slow, deep breathing in reducing somatic pain. We did not provide any instruction for slow, deep breathing to be "relaxing." Moreover, slow, deep breathing can also influence other dimensions of emotion such as perceived control and valence, ${ }^{38}$ which may influence pain experience. ${ }^{53}$ Weltens et al. ${ }^{54}$ found that valence, but not arousal, mediates the effect of emotion induction on visceral pain. Whether the 


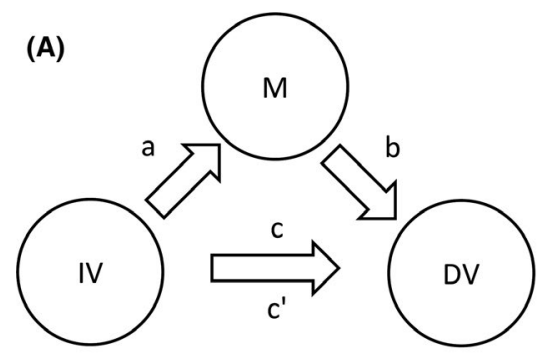

(B)
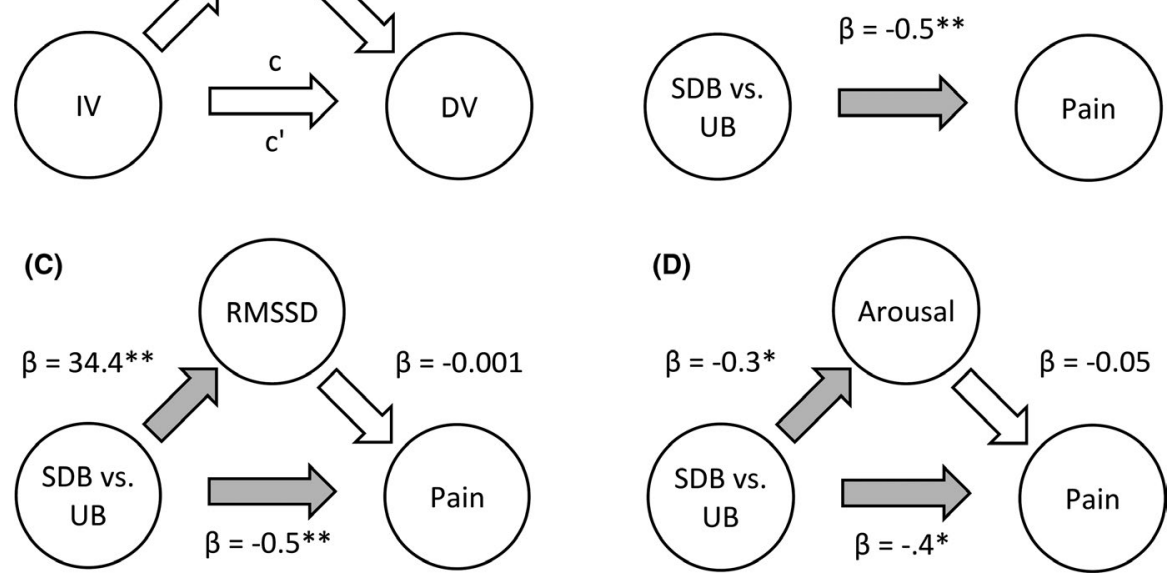

FIGURE 4 Mediation analysis. A, Mediation model. IV: independent variable, DV: dependent variable, M: mediator, a: X $\Rightarrow>$ M relationship, b: $M \Rightarrow>$ relationship, $c: X \Rightarrow Y$ total relationship, $c^{\prime}$ : unmediated $X \Rightarrow Y$ relationship (residual). Mediation analysis examining the effect of slow, deep breathing (SDB) vs. uncontrolled breathing (UB) on pain intensity with total effect (model B), with the mediator as pre-stimulus root mean square of successive differences (RMSSD, model C), and with the mediator as pre-stimulus arousal (model D). Data are coefficients for models B and C and estimate for model D. Arrows indicate significant association; ${ }^{*} p<.01,{ }^{* *} p<.001$

TABLE 2 Association of demographic and baseline characteristics with pain intensity and possible interactions with the breathing condition

\begin{tabular}{|c|c|c|}
\hline & $F$ & $P$ \\
\hline Gender & 0.25 & .618 \\
\hline Condition $\times$ gender & 0.24 & .791 \\
\hline Pain catastrophizing ${ }^{a}$ & 0.23 & .633 \\
\hline Condition $\times$ pain catastrophizing & 3.60 & .027 \\
\hline Fear of pain ${ }^{a}$ & 0.03 & .861 \\
\hline Condition $\times$ fear of pain & 1.43 & .239 \\
\hline Baseline RR-interval $^{\mathrm{a}}$ & 6.58 & .013 \\
\hline Condition $\times$ baseline RR-interval & 1.92 & .147 \\
\hline Baseline RMSSD ${ }^{a}$ & 25.24 & $<.001$ \\
\hline Condition $\times$ baseline RMSSD & 0.75 & .470 \\
\hline Baseline BRS ${ }^{a}$ & 18.40 & $<.001$ \\
\hline Condition $\times$ baseline BRS & 1.20 & .302 \\
\hline
\end{tabular}

Abbreviations: BRS, baroreflex sensitivity; RMSSD, root mean square of successive differences.

${ }^{\mathrm{a}}$ Standardized $($ mean $=0$, standard deviation $=1$ ) variables.

effect of slow, deep breathing on visceral pain is mediated through emotional modulation and whether such effect can be potentiated with specific instructions require further investigations and a more comprehensive evaluation of the emotional state.

\subsection{3 | Attentional modulation}

Controlled breathing requires sustained attention to an external (visual, auditory) or internal (counting) cue and altering breathing behavior. This can re-allocate attention from pain to breathing which in turn may influence pain perception. ${ }^{55}$ The effect of attention modulation on pain depends on, among others, the distracter and to what extent it can reduce or interfere with attention to pain. ${ }^{56} \mathrm{We}$ used an active control condition (controlled breathing at a normal breathing frequency) assuming it would require the same attentional demand as slow, deep breathing. Mean RR-interval was slightly, but similarly, lower during the two controlled breathing conditions (vs. uncontrolled breathing) in our study. This might be related to a higher cognitive workload due to competing attentional demands, pain vs. controlled breathing. ${ }^{57}$ Our findings are similar to previous studies on somatic pain that used the same active control condition and found no effect of slow, deep breathing over control on somatic pain. ${ }^{2,48}$

An interesting finding in our study was a moderating effect of pain catastrophizing on controlled breathing hypoalgesia which supports distraction as the potential mechanism for the observed effect of slow, deep breathing on pain. In contrast, such interaction has not been observed with placebo analgesia. ${ }^{27}$ Although the overall difference in pain intensity between controlled breathing and uncontrolled breathing was about 0.5 point (out of 10 ), this difference increased to about 1 point in those with higher pain catastrophizing scores. Catastrophizing demands cognitive-attentional resources. ${ }^{58}$ Controlled breathing may interfere with the ability to catastrophize about the pain by re-allocating attention away from pain to breathing. A study in chronic pain patients, ${ }^{59}$ as well as an experimental study, ${ }^{60}$ showed that distraction produces greater analgesia among those with higher catastrophizing. Parameters such as the threat value of pain ${ }^{61}$ and motivation ${ }^{62}$ may also alter the moderating effect of pain catastrophizing on attentional modulation of pain. 


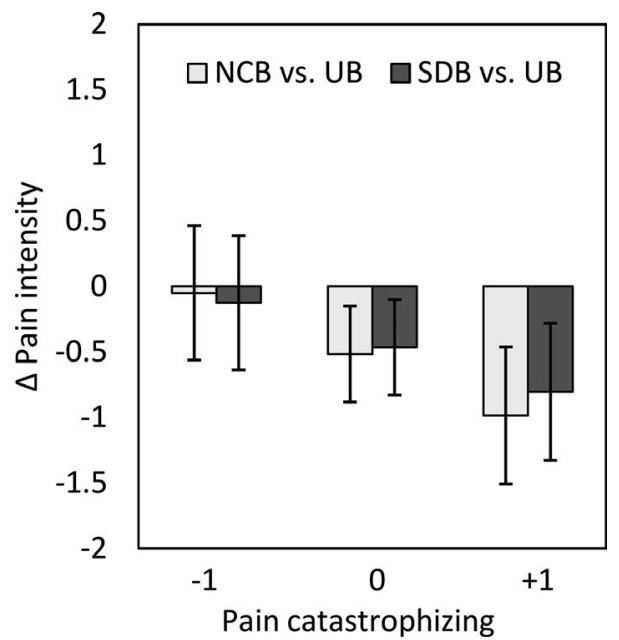

FIGURE 5 Interaction between pain catastrophizing (standardized as mean $=0$ and standard deviation $=1$ ) and breathing condition. Abbreviations: NCB, normal controlled breathing; SDB, slow, deep breathing; UB, uncontrolled breathing. Data are presented as least-squares means $\pm 2 \mathrm{SE}$

\subsection{4 | Expectancy effect}

A role of outcome expectations in the influence of mind-body interventions (eg, mindfulness meditation) on pain has recently been highlighted. ${ }^{63,64}$ To control for the potential effects of expectations, we used an active control condition similar as possible to the slow, deep breathing condition and provided no positive suggestion toward any of the controlled breathing conditions. Hence, we expected normal controlled breathing to induce similar expectations as with slow, deep breathing in influencing pain. We did not measure expectancy in this experiment. However, a separate experimental study (on the influence of placebo learning on pain) in our group found that normal controlled breathing and slow, deep breathing induce similar expectations in healthy volunteers in reducing pain ( $d=0.07, p=0.78$, I. Courtois, unpublished data). Moreover, the moderating effect of pain catastrophizing on controlled breathing hypoalgesia is more suggestive of distraction as the underlying mechanism. Expectancy has not been systematically addressed in previous experiments on the influence of slow, deep breathing on pain. ${ }^{2}$ In a recent experimental study on the influence of slow, deep breathing on somatic pain we used a cover story to limit the effect of expectancy and found no difference between slow, deep breathing and active control in pain outcomes. ${ }^{48}$ Given several factors influencing expectancy (eg, written and verbal instructions before and during the experiment as well as non-verbal behavior of the experimenter ${ }^{65}$ ) and that only a few of the previous experiments have used an active control condition, expectancy may, at least in part, explain the discrepancies between the results of previous studies. ${ }^{2}$

\subsection{Factors associated with pain}

In our study, higher mean RR-interval, RMSSD (vmHRV), and baroreflex sensitivity during baseline were associated with lower pain intensity. Associations of vmHRV and baroreflex sensitivity with somatic/visceral pain sensitivity have been reported before. ${ }^{66,67}$ Impaired cardiovascular regulation and impaired blood pressurerelated hypoalgesia are observed in patients with chronic pain. ${ }^{68-70}$ The cardiovascular regulatory system is a potential target for treatment in pain patients. Practicing slow, deep breathing for several weeks can induce long-term effects and increase resting baroreflex sensitivity and parasympathetic activity and reduce sympathetic activity. ${ }^{71-73}$ It is therefore possible that practicing slow, deep breathing in a longer period can reduce pain perception by improving autonomic and cardiovascular regulatory functions, this warrants to be investigated.

\section{3 | Study limitations and future directions}

This study had strengths and limitations. It was not possible to run this experiment in a completely double-blinded way. However, we used an active control condition similar (as possible) to the intervention, which allowed us to control for the potential effects of expectancy. Future studies may also use a cover story ${ }^{48}$ to limit the potential effects of expectancy on the outcomes. We used the active control condition also to control for the potential effects of distraction. However, there is no data on the degree of distraction during controlled breathing at different frequencies. We suggest future studies to use additional tests (eg, electroencephalography and evoked-related potentials ${ }^{74}$ ) to measure attentional modulation during controlled breathing at different frequencies. We measured emotional arousal while other emotional responses (eg, valence and perceived control) might also be involved in hypoalgesia associated with slow, deep breathing and should be measured in future studies. We also suggest future studies to use esophageal manometry (if feasible) for better positioning of the stimulation probe and for evaluating possible structural abnormalities (though not common in healthy asymptomatic young individuals). Finally, the effects of attentional modulation, ${ }^{75}$ emotional modulation, ${ }^{54}$ and expectancy (placebo) ${ }^{76}$ on visceral pain perception have also been shown at lower levels of the gastrointestinal tract (eg, rectum) or using other types of stimuli (eg, mechanical). It is warranted to test whether and through what mechanisms slow, deep breathing can modulate visceral pain at different levels and using different types of stimuli.

In summary, we found that slow, deep breathing can reduce visceral pain perception, but this effect was not specific to the slow breathing frequency. Slow, deep breathing was associated with increased baroreceptor stimulation and vagal modulation and reduced arousal. However, these responses were not involved in controlled breathing hypoalgesia. The findings of this study suggest that other mechanisms, notably distraction, are likely to be involved in controlled breathing hypoalgesia in the short-term, and pain catastrophizing can moderate this effect. Expectancy and placebo analgesia may also play a role in hypoalgesia associated with slow, deep breathing. We found that higher resting mean RR-interval, RMSSD, and baroreflex sensitivity are associated with lower visceral pain 
intensity. Considering the effect of long-term slow, deep breathing practice on the cardiovascular regulatory system, it is warranted to test whether slow, deep breathing can influence visceral pain perception when practiced for a longer period. The results of this experimental study should be replicated in patients with visceral pain conditions. The association of psychological factors (eg, catastrophizing, anxiety) and pain are extensively investigated in patients with disorders of gut-brain interaction. ${ }^{77}$ Pain inhibition by attentional modulation and expectancy have been shown in this population. ${ }^{75,76}$ Also, some studies have found dysregulation of the autonomic nervous system in patients with irritable bowel syndrome. ${ }^{78}$ However, the influence of the brain-gut axis is beyond the functional disorders and patients with other painful gastrointestinal conditions (eg, inflammatory bowel diseases) may also benefit from psychophysiological effects of slow, deep breathing. ${ }^{79}$

\section{ACKNOWLEDGMENTS}

AGh was funded by a grant from the KU Leuven Special Research Fund to JV and LVO (DBOF/14/02); LVO is funded by the KU Leuven Special Research Fund; JT and LVO are supported by a long-term structural funding Methusalem grant by the Flemish Government, Belgium (METH/14/05). JV and IVD are supported by the Asthenes long-term structural funding Methusalem grant by the Flemish Government, Belgium (METH/15/011). AP was funded by an FWO post-doctoral fellowship. The funding sources had no role in study design; in the collection, analysis and interpretation of data; in the writing of the report; or in the decision to submit the article for publication. Authors would like to thank Mathijs Franssen and Jeroen Clarysse (Health Psychology, KU Leuven) for providing technical support during this study.

\section{CONFLICT OF INTEREST}

QA serves as a consultant for Grunenthal Pharma, Allergan, and Pantheryx and received conference support from Alimentary Health. JT has given scientific advice to AlfaWassermann, Allergan, Christian Hansen, Danone, Grünenthal, Ironwood, Janssen, Kiowa Kirin, Menarini, Mylan, Neutec, Novartis, Noventure, Nutricia, Shionogi, Shire, Takeda, Theravance, Tramedico, Truvion, Tsumura, Zealand and Zeria pharmaceuticals and has served on the speaker bureau for Abbott, Allergan, AstraZeneca, Janssen, Kyowa Kirin, Menarini, Mylan, Novartis, Shire, Takeda, Truvion and Zeria. LVO received an unrestricted research grant from Nestlé and serves as a consultant for Danone. Other authors have no potential conflict of interest.

\section{AUTHORS' CONTRIBUTIONS}

AGh involved in study protocol, data collection, data processing, statistical analysis, and manuscript preparation. LVO involved in statistical analysis. All authors involved in study protocol revision, data interpretation, manuscript revision, approved the final version to be published and agree to be accountable for all aspects of the work in ensuring that questions related to the accuracy or integrity of any part of the work are appropriately investigated and resolved.

\section{ORCID}

Ali Gholamrezaei (D) https://orcid.org/0000-0001-8674-450X

Ilse Van Diest (D) https://orcid.org/0000-0002-0048-774X

Qasim Aziz (D) https://orcid.org/0000-0002-2718-2065

Jan Tack (D) https://orcid.org/0000-0002-3206-6704

Johan W. S. Vlaeyen (D) https://orcid.org/0000-0003-0437-6665

Lukas Van Oudenhove (D) https://orcid.org/0000-0002-6540-3113

\section{REFERENCES}

1. Nahin RL, Stussman BJ, Herman PM. Out-of-pocket expenditures on complementary health approaches associated with painful health conditions in a nationally representative adult sample. J Pain. 2015;16(11):1147-1162. https://doi.org/10.1016/j. jpain.2015.07.013.

2. Jafari H, Courtois I, Van den Bergh O, Vlaeyen JWS, Van Diest I. Pain and respiration: a systematic review. Pain. 2017;158(6):9951006. https://doi.org/10.1097/j.pain.0000000000000865.

3. Mazzone SB, Undem BJ. Vagal afferent innervation of the airways in health and disease. Physiol Rev. 2016;96(3):975-1024. https://doi. org/10.1152/physrev.00039.2015.

4. Gholamrezaei A, Van Diest I, Aziz Q, Vlaeyen JWS, Van Oudenhove L. Influence of inspiratory threshold load on cardiovascular responses to controlled breathing at $0.1 \mathrm{~Hz}$. Psychophysiology. 2019;56(11):e13447. https://doi.org/10.1111/psyp.13447.

5. Gholamrezaei A, Van Diest I, Aziz Q, Vlaeyen JWS, Van Oudenhove L. Psychophysiological responses to various slow, deep breathing techniques. Psychophysiology. 2021;58(2):e13712. https://doi. org/10.1111/psyp.13712.

6. Benarroch EE. The arterial baroreflex: functional organization and involvement in neurologic disease. Neurology. 2008;71(21):17331738. https://doi.org/10.1212/01.wnl.0000335246.93495.92.

7. Bruehl S, Chung OY. Interactions between the cardiovascular and pain regulatory systems: an updated review of mechanisms and possible alterations in chronic pain. Neurosci Biobehav Rev. 2004;28(4):395-414. https://doi.org/10.1016/j.neubi orev.2004.06.004.

8. Takeda M, Tanimoto T, Ojima K, Matsumoto S. Suppressive effect of vagal afferents on the activity of the trigeminal spinal neurons related to the jaw-opening reflex in rats: involvement of the endogenous opioid system. Brain Res Bull. 1998;47(1):49-56. https://doi. org/10.1016/s0361-9230(98)00059-8.

9. Dworkin BR, Elbert T, Rau H, et al. Central effects of baroreceptor activation in humans: attenuation of skeletal reflexes and pain perception. Proc Natl Acad Sci USA. 1994;91(14):6329-6333. https:// doi.org/10.1073/pnas.91.14.6329.

10. Mini A, Rau H, Montoya P, Palomba D, Birbaumer N. Baroreceptor cortical effects, emotions and pain. Int J Psychophysiol. 1995;19(1):67-77. https://doi.org/10.1016/0167-8760(94)00084 -R.

11. Randich A, Gebhart GF. Vagal afferent modulation of nociception. Brain Res Rev. 1992;17(2):77-99. https://doi. org/10.1016/0165-0173(92)90009-B.

12. Reyes del Paso GA, Montoro C, Muñóz Ladrón de Guevara C, Duschek S, Jennings JR. The effect of baroreceptor stimulation on pain perception depends on the elicitation of the reflex cardiovascular response: evidence of the interplay between the two branches of the baroreceptor system. Biol Psychol. 2014;101(1):8290. https://doi.org/10.1016/j.biopsycho.2014.07.004.

13. Sévoz-Couche C, Hamon M, Laguzzi R. Antinociceptive effect of cardiopulmonary chemoreceptor and baroreceptor reflex activation in the rat. Pain. 2002;99(1-2):71-81. https://doi.org/10.1016/ S0304-3959(02)00055-6. 
14. Bohotin C, Scholsem M, Bohotin V, Franzen R, Schoenen J. Vagus nerve stimulation attenuates heat- and formalin-induced pain in rats. Neurosci Lett. 2003;351(2):79-82. https://doi.org/10.1016/ s0304-3940(03)00908-x.

15. Busch V, Zeman F, Heckel A, Menne F, Ellrich J, Eichhammer P. The effect of transcutaneous vagus nerve stimulation on pain perception - an experimental study. Brain Stimul. 2013;6(2):202-209. https://doi.org/10.1016/j.brs.2012.04.006.

16. Van Oudenhove L, Kragel PA, Dupont P, et al. Common and distinct neural representations of aversive somatic and visceral stimulation in healthy individuals. Nat Commun. 2020;11(1):5939. https://doi. org/10.1038/s41467-020-19688-8.

17. Koenen LR, Elsenbruch S. Schmerz ist modalitätsspezifisch. Der Schmerz. 2018;32(2):139-143. https://doi.org/10.1007/s0048 2-018-0281-y.

18. Koenen LR, Icenhour A, Forkmann K, et al. Greater fear of visceral pain contributes to differences between visceral and somatic pain in healthy women. Pain. 2017;158(8):1599-1608. https://doi. org/10.1097/j.pain.0000000000000924.

19. Mclntyre D, Edwards L, Ring C, Parvin B, Carroll D. Systolic inhibition of nociceptive responding is moderated by arousal. Psychophysiology. 2006;43(3):314-319. https://doi. org/10.1111/j.1469-8986.2006.00407.x.

20. Martins AQ, Ring C, Mclntyre D, Edwards L, Martin U. Effects of unpredictable stimulation on pain and nociception across the cardiac cycle. Pain. 2009;147(1-3):84-90. https://doi.org/10.1016/j. pain.2009.08.016.

21. Botha C, Farmer AD, Nilsson M, et al. Preliminary report: modulation of parasympathetic nervous system tone influences oesophageal pain hypersensitivity. Gut. 2015;64(4):611-617. https://doi. org/10.1136/gutjnl-2013-306698.

22. Jafari H, Gholamrezaei A, Franssen M, et al. Can slow deep breathing reduce pain? An experimental study exploring mechanisms. $J$ Pain. 2020;21(9-10):1018-1030. https://doi.org/10.1016/j. jpain.2019.12.010

23. Kroenke K, Spitzer RL, Williams JBW, Lowe B. The Patient Health Questionnaire Somatic, Anxiety, and Depressive Symptom Scales: a systematic review. Gen Hosp Psychiatry. 2010;32(4):345-359. https://doi.org/10.1016/j.genhosppsych.2010.03.006.

24. Imholz BPM, Wieling W, Van Montfrans GA, Wesseling KH. Fifteen years experience with finger arterial pressure monitoring: assessment of the technology. Cardiovasc Res. 1998;38(3):605-616. https://doi.org/10.1016/S0008-6363(98)00067-4.

25. Spruyt A, Clarysse J, Vansteenwegen D, Baeyens F, Hermans D. Affect 4.0: a free software package for implementing psychological and psychophysiological experiments. Exp Psychol. 2010;57(1):3645. https://doi.org/10.1027/1618-3169/a000005.

26. Price DD, McGrath PA, Rafii A, Buckingham B. The validation of visual analogue scales as ratio scale measures for chronic and experimental pain. Pain. 1983;17(1):45-56. https://doi. org/10.1016/0304-3959(83)90126-4.

27. Lu HC, Hsieh JC, Lu CL, et al. Neuronal correlates in the modulation of placebo analgesia in experimentally-induced esophageal pain: a 3T-fMRI study. Pain. 2010;148(1):75-83. https://doi.org/10.1016/j. pain.2009.10.012

28. Bradley MM, Lang PJ. Measuring emotion: the self-assessment manikin and the semantic differential. J Behav Ther Exp Psychiatry. 1994;25(1):49-59. https://doi.org/10.1016/0005-7916(94)90063 $-9$.

29. Sullivan MJL, Bishop SR, Pivik J. The Pain Catastrophizing Scale: development and validation. Psychol Assess. 1995;7(4):524-532. https://doi.org/10.1037/1040-3590.7.4.524.

30. McNeil DW, Kennedy SG, Randall CL, et al. Fear of Pain Questionnaire-9: brief assessment of pain-related fear and anxiety. Eur J Pain. 2018;22(1):39-48. https://doi.org/10.1002/ejp.1074.
31. Aziz Q, Thompson DG, Ng VW, et al. Cortical processing of human somatic and visceral sensation. J Neurosci. 2000;20(7):2657-2663.

32. Molina Caballero AY, Villar Varela ME, Perez Martinez A, Ayuso Gonzalez L, Hernandez Martin S, Goni OC. Placement of $\mathrm{pH}$ monitoring probes using height-related formulas. Is it an applicable method to adults? Gastroenterol Hepatol. 2016;39(4):261-264. https://doi.org/10.1016/j.gastrohep.2015.08.002.

33. Hobson AR, Chizh B, Hicks K, et al. Neurophysiological evaluation of convergent afferents innervating the human esophagus and area of referred pain on the anterior chest wall. Am J Physiol Gastrointest Liver Physiol. 2010;298(1):G31-G36. https://doi.org/10.1152/ ajpgi.00288.2009.

34. Farmer AD, Coen SJ, Kano M, et al. Psychological traits influence autonomic nervous system recovery following esophageal intubation in health and functional chest pain. Neurogastroenterol Motil. 2013;25(12):950-e772. https://doi.org/10.1111/nmo.12231.

35. Drewes AM, Gregersen H, Arendt-Nielsen L. Experimental pain in gastroenterology: a reappraisal of human studies. Scand J Gastroenterol. 2003;38(11):1115-1130. https://doi. org/10.1080/00365520310004399.

36. Rhudy JL, France CR. Reliability and validity of a brief method to assess nociceptive flexion reflex (NFR) threshold. J Pain. 2011;12(7):782-791. https://doi.org/10.1016/j. jpain.2011.01.002.

37. Frobert $\mathrm{O}$, Arendt-Nielsen L, Bak $\mathrm{P}$, Andersen $\mathrm{OK}$, Funch-Jensen $\mathrm{P}$, Bagger JP. Electric stimulation of the esophageal mucosa. Perception and brain-evoked potentials. Scand J Gastroenterol. 1994;29(9):776781. https://doi.org/10.3109/00365529409092509.

38. Van Diest I, Verstappen K, Aubert AE, Widjaja D, Vansteenwegen $D$, Vlemincx E. Inhalation/Exhalation ratio modulates the effect of slow breathing on heart rate variability and relaxation. Appl Psychophysiol Biofeedback. 2014;39(3-4):171-180. https://doi. org/10.1007/s10484-014-9253-x.

39. Task Force of the European Society of Cardiology and the North American Society of Pacing and Electrophysiology. Heart rate variability: standards of measurement, physiological interpretation and clinical use. Circulation. 1996;93(5):1043-1065. https://doi. org/10.1161/01.CIR.93.5.1043.

40. La Rovere MT, Pinna GD, Raczak G. Baroreflex sensitivity: measurement and clinical implications. Ann Noninvasive Electrocardiol. 2008;13(2):191-207. https://doi. org/10.1111/j.1542-474X.2008.00219.x.

41. Boucsein W, Fowles DC, Grimnes S, et al. Publication recommendations for electrodermal measurements. Psychophysiology. 2012;49(8):1017-1034. https://doi. org/10.1111/j.1469-8986.2012.01384.x.

42. Faul F, Erdfelder E, Lang A-G, Buchner A. G*Power 3: a flexible statistical power analysis program for the social, behavioral, and biomedical sciences. Behav Res Methods. 2007;39(2):175-191. https:// doi.org/10.3758/BF03193146.

43. Holm S. A simple sequentially rejective multiple test procedure. Source Scand J Stat. 1979;6(2):65-70. https://doi. org/10.2307/4615733.

44. Lakens D. Calculating and reporting effect sizes to facilitate cumulative science: a practical primer for t-tests and ANOVAs. Front Psychol. 2013;4(November):1-12. https://doi.org/10.3389/ fpsyg.2013.00863.

45. Nussinovitch U, Elishkevitz KP, Katz K, et al. Reliability of ultra-short ECG indices for heart rate variability. Ann Noninvasive Electrocardiol. 2011;16(2):117-122. https://doi. org/10.1111/j.1542-474X.2011.00417.x.

46. Wager TD, Davidson ML, Hughes BL, Lindquist MA, Ochsner KN. Prefrontal-subcortical pathways mediating successful emotion regulation. Neuron. 2008;59(6):1037-1050. https://doi.org/10.1016/j. neuron.2008.09.006. 
47. Martin SL, Kerr KL, Bartley EJ, et al. Respiration-induced hypoalgesia: exploration of potential mechanisms. J Pain. 2012;13(8):755763. https://doi.org/10.1016/j.jpain.2012.05.001.

48. Gholamrezaei A, Van Diest I, Aziz Q, Vlaeyen JWS, Van Oudenhove L. Controlled breathing and pain: respiratory rate and inspiratory loading modulate cardiovascular autonomic responses, but not pain. Psychophysiology. 2021;e13895. https://doi.org/10.1111/ psyp.13895. [Online ahead of print]

49. Abrams P, Andersson K-E, Buccafusco JJ, et al. Muscarinic receptors: their distribution and function in body systems, and the implications for treating overactive bladder. $\mathrm{Br} J$ Pharmacol. 2006;148(5):565-578. https://doi.org/10.1038/sj.bjp.0706780.

50. McCaul KD, Solomon S, Holmes DS. Effects of paced respiration and expectations on physiological and psychological responses to threat. J Pers Soc Psychol. 1979;37(4):564-571. https://doi.org/10.1 037//0022-3514.37.4.564.

51. Cappo BM, Holmes DS. The utility of prolonged respiratory exhalation for reducing physiological and psychological arousal in non-threatening and threatening situations. J Psychosom Res. 1984;28(4):265-273. https://doi.org/10.1016/0022-3999(84)90048-5.

52. Busch V, Magerl W, Kern U, Haas J, Hajak G, Eichhammer P. The effect of deep and slow breathing on pain perception, autonomic activity, and mood processing - an experimental study. Pain Med. 2012;13(2):215-228. https://doi. org/10.1111/j.1526-4637.2011.01243.x.

53. Wiech K, Kalisch R, Weiskopf N, Pleger B, Stephan KE, Dolan RJ. Anterolateral prefrontal cortex mediates the analgesic effect of expected and perceived control over pain. J Neurosci. 2006;26(44):11501-11509. https://doi.org/10.1523/JNEUR OSCI.2568-06.2006.

54. Weltens N, Brunner-Schaub N, Farmer AD, et al. 789 - Fear of pain and serotonergic gene polymorphisms are associated with interindividual variability in positive and negative emotional modulation of visceral pain in health. Gastroenterology. 2019;156(6):S-165S-166. https://doi.org/10.1016/S0016-5085(19)37206-3.

55. Bushnell MC, Ceko M, Low LA. Cognitive and emotional control of pain and its disruption in chronic pain. Nat Rev Neurosci. 2013;14(7):502-511. https://doi.org/10.1038/nrn3516.

56. Birnie KA, Chambers CT, Spellman CM. Mechanisms of distraction in acute pain perception and modulation. Pain. 2017;158(6):10121013. https://doi.org/10.1097/j.pain.0000000000000913.

57. Eccleston C, Crombez G. Pain demands attention: a cognitiveaffective model of the interruptive function of pain. Psychol Bull. 1999;125(3):356-366. https://doi.org/10.1037/003 3-2909.125.3.356.

58. Sullivan MJ, Thorn B, Haythornthwaite JA, et al. Theoretical perspectives on the relation between catastrophizing and pain. Clin J Pain. 2001;17(1):52-64.

59. Schreiber KL, Campbell C, Martel MO, et al. Distraction analgesia in chronic pain patients: the impact of catastrophizing. Anesthesiology. 2014;121(6):1292-1301. https://doi.org/10.1097/ALN.00000 00000000465 .

60. Rischer KM, González-Roldán AM, Montoya P, Gigl S, Anton F, van der Meulen M. Distraction from pain: the role of selective attention and pain catastrophizing. Eur J Pain (United Kingdom). 2020;24(10):1880-1891. https://doi.org/10.1002/ejp.1634.

61. Jackson T, Yang Z, Li X, Chen H, Huang X, Meng J. Coping when pain is a potential threat: the efficacy of acceptance versus cognitive distraction. Eur J Pain. 2012;16(3):390-400. https://doi. org/10.1002/j.1532-2149.2011.00019.x.

62. Verhoeven K, Crombez G, Eccleston C, Van Ryckeghem DML, Morley S, Van Damme S. The role of motivation in distracting attention away from pain: an experimental study. Pain. 2010;149(2):229234. https://doi.org/10.1016/j.pain.2010.01.019.
63. Case L, Adler-Neal AL, Wells RE, Zeidan F. The role of expectations and endogenous opioids in mindfulness-based relief of experimentally-induced acute pain. Psychosom Med. 2021;83(6):549-556. https://doi.org/10.1097/PSY.0000000000 000908

64. Davies JN, Sharpe L, Day MA, Colagiuri B. Mindfulness-based analgesia or placebo effect? The development and evaluation of a sham mindfulness intervention for acute experimental pain. Psychosom Med. 2021;83(6):557-565. https://doi.org/10.1097/PSY.00000 00000000886

65. Chen PA, Cheong JH, Jolly E, Elhence H, Wager TD, Chang LJ. Socially transmitted placebo effects. Nat Hum Behav. 2019;3(12):12951305. https://doi.org/10.1038/s41562-019-0749-5.

66. Ruffle JK, Coen SJ, Giampietro V, Williams SCR, Aziz Q, Farmer AD. Preliminary report: parasympathetic tone links to functional brain networks during the anticipation and experience of visceral pain. Sci Rep. 2018;8(1):13410. https://doi.org/10.1038/s41598-01831522-2.

67. Suarez-Roca H, Klinger RY, Podgoreanu MV, et al. Contribution of baroreceptor function to pain perception and perioperative outcomes. Anesthesiology. 2019;130:634-650. https://doi. org/10.1097/ALN.0000000000002510.

68. Bruehl S, Olsen RB, Tronstad C, et al. Chronic pain-related changes in cardiovascular regulation and impact on comorbid hypertension in a general population: the Tromso study. Pain. 2018;159(1):119127. https://doi.org/10.1097/j.pain.0000000000001070.

69. Olsen RB, BruehI S, Nielsen CS, Rosseland LA, Eggen AE, Stubhaug A. Hypertension prevalence and diminished blood pressure-related hypoalgesia in individuals reporting chronic pain in a general population: the Tromso study. Pain. 2013;154(2):257-262. https://doi. org/10.1016/j.pain.2012.10.020.

70. Bruehl S, Chung OY, Diedrich L, Diedrich A, Robertson D. The relationship between resting blood pressure and acute pain sensitivity: effects of chronic pain and alpha-2 adrenergic blockade. J Behav Med. 2008;31(1):71-80. https://doi.org/10.1007/s1086 5-007-9133-4.

71. Lehrer PM, Vaschillo E, Vaschillo B, et al. Heart rate variability biofeedback increases baroreflex gain and peak expiratory flow. Psychosom Med. 2003;65(5):796-805. https://doi.org/10.1097/01. psy.0000089200.81962.19.

72. Laborde S, Hosang T, Mosley E, Dosseville F. Influence of a 30-day slow-paced breathing intervention compared to social media use on subjective sleep quality and cardiac vagal activity. J Clin Med. 2019;8(2):193. https://doi.org/10.3390/jcm8020193.

73. Chaddha A, Modaff D, Hooper-Lane C, Feldstein DA. Device and non-device-guided slow breathing to reduce blood pressure: a systematic review and meta-analysis. Complement Ther Med. 2019;45:179-184. https://doi.org/10.1016/j.ctim.2019.03.005.

74. Legrain V, Crombez G, Plaghki L, Mouraux A. Shielding cognition from nociception with working memory. Cortex. 2013;49(7):19221934. https://doi.org/10.1016/j.cortex.2012.08.014.

75. Dunckley P, Aziz Q, Wise RG, Brooks J, Tracey I, Chang L. Attentional modulation of visceral and somatic pain. Neurogastroenterol Motil. 2007;19(7):569-577. https://doi. org/10.1111/j.1365-2982.2007.00908.x.

76. Price DD, Craggs J, Nicholas Verne G, Perlstein WM, Robinson ME. Placebo analgesia is accompanied by large reductions in painrelated brain activity in irritable bowel syndrome patients. Pain. 2007;127(1-2):63-72. https://doi.org/10.1016/j.pain.2006.08.001.

77. Van Oudenhove L, Crowell MD, Drossman DA, et al. Biopsychosocial aspects of functional gastrointestinal disorders. Gastroenterology. 2016;150(6):1355-1367.e2. https://doi.org/10.1053/j.gastro.2016. 02.027. 
78. Salvioli B, Pellegatta G, Malacarne M, et al. Autonomic nervous system dysregulation in irritable bowel syndrome. Neurogastroenterol Motil. 2015;27(3):423-430. https://doi.org/10.1111/nmo.12512.

79. Gracie DJ, Hamlin PJ, Ford AC. The influence of the brain-gut axis in inflammatory bowel disease and possible implications for treatment. Lancet Gastroenterol Hepatol. 2019;4(8):632-642. https://doi. org/10.1016/S2468-1253(19)30089-5.

\section{SUPPORTING INFORMATION}

Additional supporting information may be found online in the Supporting Information section.
How to cite this article: Gholamrezaei A, Van Diest I, Aziz Q, et al. Effect of slow, deep breathing on visceral pain perception and its underlying psychophysiological mechanisms. Neurogastroenterology \& Motility.

2021;00:e14242. https://doi.org/10.1111/nmo.14242 